\title{
Evaluation of seven gene signature for predicting HCV recurrence post-liver transplantation
}

\author{
Ghada M. Salum', Mai Abd el Meguid', Tawfeek H. Abelhafez', Eman Medhat², Ashraf O. Abdel Aziz² and \\ Reham Dawood ${ }^{1 *}$ (1)
}

\begin{abstract}
Background: Orthotropic liver transplantation (OLT) offers a therapeutic choice for hepatocellular carcinoma (HCC) patients. The poor outcome of liver transplantation is HCV recurrence. Several genome-wide associated studies (GWAS) have reported many genetic variants to be associated with HCV recurrence. Seven gene polymorphisms formed a cirrhosis risk score (CRS) signature that could be used to distinguish chronic HCV patients at high risk from those at low risk for cirrhosis in non-transplant patients. This study aims to examine the association of CRS score and other clinical parameters with the probability for HCC emergence and/or the rate of HCV recurrence following liver transplantation.
\end{abstract}

Results: Seven gene polymorphisms, forming the CRS, were genotyped by real-time PCR using allelic discrimination protocol in 199 end-stage liver disease patients (79 child A, 43 child B, and 77child C), comprising 106 patients who encountered liver transplantation. Recipient CRS scores were correlated with HCV recurrence (HCV-Rec) at the end of the third year after OLT. Around 81\% (39) recipients with low steatosis (LS; $<3.5 \%)$ donor percentage revealed no HCV recurrence (non-Rec) $(p<0.001)$. CRS score could distinguish between child $A$, child $B$, and child $C$ only at the low-risk group. Among the HCV Rec group 27\% (8/30), 40\% (12/30), and 33\% (10/30) fell into the high, moderate, and low CRS risk groups, respectively. Stepwise logistic regression evinced two features more likely to be seen in HCV-Rec patients: abnormal ALT [OR, 1.1; 95\% Cl, 1.02-1.2] and donor steatosis >3.5\% [OR, 46.07; 95\% Cl, 1.5-1407.8].

Conclusions: Accordingly, the CRS score seems to be less useful to predict HCV recurrence after OLT. ALT and donor steatosis (exceed 3.5\%) can significantly promote the HCV recurrence post-OLT. Moreover, the combination of MMF and CNI positively heightens HCV recurrence.

Keywords: HCV, CRS, Donor steatosis, Recipients, Orthotropic liver transplantation, SNP, Allelic discrimination

\section{Background}

Despite the incredible progress in treating hepatitis $C$ virus ( $\mathrm{HCV})$, many patients are still at the risk of disease progression to cirrhosis and hepatocellular carcinoma (HCC) at different rates [1-3]. Our country launched "100 million lives" campaign declaring that

\footnotetext{
*Correspondence: rmhaemd@hotmail.com

${ }^{1}$ Department of Microbial Biotechnology, Genetic Engineering Division,

National Research Centre, Dokki, P.O. 12622, Giza, Egypt

Full list of author information is available at the end of the article
}

viral hepatitis should be eliminated by 2030 . Elimination of HCV will confer economic benefits and substantial health and, most critically, the avoidance of above 1.2 million deaths yearly [4]. The Child-Pugh score has been used as a prognostic predictor of postoperative mortality and has been taken into account in a number of staging systems [5, 6]. To date, surgery remains the master prognostic tool for the long-term survival of HCC patients; nevertheless, HCC is frequently associated with chronic viral hepatitis and over $80 \%$ of tumors are unresectable $[7,8]$. OLT submits a 
therapeutic choice for HCC patients, particularly in cirrhotic patients without distant metastasis of HCC.

Nonetheless, the main potential cause for the poor outcome of liver transplanted patients post-OLT is $\mathrm{HCV}$ recurrence [9]. Recurrent $\mathrm{HCV}$-associated liver disease leads to a consequent loss of graft in about one third of patients within 5 years of OLT and recurrent $\mathrm{HCV}$-associated graft failure is the main cause of patient mortality and re-transplantation in the 5th postoperative year [10]. Several factors are crucial to minimize the complications and improve the clinical outcome such as choice of a suitable donor, appropriate immunosuppressive treatment, and genetic risk stratification prior to transplantation $[11,12]$.

Data on the genetic risk of $\mathrm{HCV}$ recurrence postliver transplantation are scarce [13]. Recent data on Toll-like receptor (TLR)-related genes have recorded an augmented risk of HCC recurrence for donor's TLR4 (rs1927914) and recipient's TLR9 (rs187084) and IL-15 (rs10519613) polymorphisms, respectively [14-16]. Additionally, the model for end-stage liver disease (MELD), AST to platelet ratio index (APRI), and fibrosis scoring system (FIB-4) was used to evaluate liver fibrosis post-LT for HCV-related liver disease [17], while some skepticism was stated about these scores [18].

Up to date, no study delineate-specific predictive biomarkers of $\mathrm{HCV}$ recurrence in post-transplant patients [19]. Cirrhosis Risk Score (CRS) is a polygenic signature firstly defined by Huang [20] and stratified the cirrhosis risk in many populations better than clinical factors $[20,21]$. CRS is relying on a set of seven single-nucleotide polymorphisms (SNPs) in six genes: AP3S2, AQP2, AZIN1, STXBP5L, TLR4, TRPM5, and in the intergenic region between DEGS1 and NVL (see Table 1).

Theoretically, CRS may be used to stratify patients who are eligible for OLT or not better than a liver biopsy. The latter represents a single time point in the extended natural history of chronic infection, while genetic markers are and "life-long." Also, we have a growing base of evidence linking a variant in the IL6 rs1800795 G allele with HCV recurrence post-LT [28]. Moreover, we finished a promising study which validated CRS performance in 240 Egyptian HCV-infected patients with different fibrosis grades [29]. Herein, to fuel the novel debate on Child-Pugh score, we assess it with a CRS signature (as an intrinsic genetic marker). Moreover, we aim to validate a CRS signature for recipients to assess the risk for $\mathrm{HCV}$ recurrence following OLT in Egyptian liver transplanted patients as it may serve as an early noninvasive genetic biomarker for HCV recurrence post-OLT.

\section{Methods}

\section{Study design}

The study included a total of 199 end-stage liver disease patients (79 child A, 43 child B, and 77 child C); comprising 106 patients who encountered OLT. All patients encountered orthotopic LT for HCV. The histologic degree of macrovesicular steatosis was determined. Patients suffering from acute rejection episodes were excluded. The primary immunosuppressive for all patients consisted of a calcineurin inhibitor (CNI) with or without Mycophenolate mofetil (MMF) or Everolimus at the second year (according to specific side effects or renal function). In this study, the patients were divided into two groups according to the HCV recurrence: group 1 , HCV Rec group $(n=32)$ and group 2 , non-Rec group $(n=48)$.

All patients were also evaluated by clinical and laboratory parameters, including biochemical (alanine aminotransferase (ALT), aspartate aminotransferase (AST), albumin, bilirubin total, and platelets count (Plt)), and serological test (anti-HCV) and histopathology of liver biopsy. The diagnosis of HCC was made after reviewing images generated with several imaging modalities. Patients having other cancers were excluded.

Table 1 General details on the 7 candidate SNPs in the CRS score

\begin{tabular}{lllll}
\hline Genes & Gene name & rs number & Chromosome & Gene biological functions \\
\hline AZIN1 & Antizyme inhibitor & rs62522600 & $\mathbf{( C h r 8 )}$ & Polyamine biosynthesis, cell proliferation [22] \\
TLR4 & Toll-like receptor 4 & rs4986791 & $\mathbf{( C h r 9 )}$ & Important pathogen recognition receptors [23] \\
TRPM5 & $\begin{array}{l}\text { Transient receptor potential cation channel subfam- } \\
\text { ily member 5 }\end{array}$ & rs886277 & $\mathbf{( C h r 1 1 )}$ & $\begin{array}{l}\text { Taste responses, specific physiological function in liver } \\
\text { is unknown [24]. }\end{array}$ \\
AP3S2 & Adaptor-related protein complex 3 sigma 2 subunit & rs2290351 & $\mathbf{( C h r 1 5 )}$ & Unknown \\
DESGS1 & $\begin{array}{l}\text { Degenerative spermatocyte homolog1 lipid desatu- } \\
\text { rase }\end{array}$ & rs4290029 & $\mathbf{( C h r 1 )}$ & Lipid metabolism and transport, cell growth [25] \\
STXBP5L & Syntaxin binding protein & rs17740066 & $\mathbf{( C h r 3 )}$ & Inhibits endothelial exocytosis [26] \\
AQP2 & Aquaporin 2 & rs2878771 & $\mathbf{( C h r 1 2 )}$ & Water reabsorption, vasopressin regulation [27] \\
\hline
\end{tabular}

SNP single-nucleotide polymorphism, $r$ s accession number on databases referring to specific SNPs 


\section{Liver biopsy evaluation}

Liver biopsy was operated for all recipients at the end of the third year following primary OLT. Liver biopsies were evaluated by a pathologist who was unaware of clinical and demographic data that were obtained. Fibrosis stages were defined using the METAVIR scoring system and categorized according to F0: none, F1: portal widening, F2: bridging fibrosis, and F3: bridging fibrosis with lobular distortion. We also stratified the fibrotic patients based on the inflammation activity into A1, A2, A3 refer to mild, moderate, and severe, respectively.

\section{Extraction of peripheral blood DNA}

The peripheral blood on EDTA was withdrawn from all subjects, and genomic DNA was extracted using genomic DNA extraction kits (Qiagen, Milan Italy). Purified genomic DNA samples were quantified using ultraviolet absorbance at $260 \mathrm{~nm}$ using a Thermo Scientific NanoDrop $^{\mathrm{TM}}$ Spectrophotometer. The DNA was stored at $-20^{\circ} \mathrm{C}$.

\section{Cirrhosis risk signature (CRS) genotyping}

The 7 SNPs identified previously by Huang et al. [20] were genotyped using a real-time PCR protocol based on the pre-validated TaqMan $\mathrm{MGB}^{\mathrm{TM}}$ probe for allelic discrimination assay (Applied Biosystems). Briefly, $1.25 \mu \mathrm{L}$ of a 40X combined primer and probe mix (ABI/Life Technologies, USA) was added to $12.5 \mu \mathrm{L}$ of $2 \mathrm{X}$ TaqMan ${ }^{\circledR}$ Universal PCR master mix (ABI/Life Technologies, USA) in a $25-\mu \mathrm{L}$ final volume of DNAse/RNAse-free water (Invitrogen/Life Technologies, USA) and template. The cycle conditions were $95{ }^{\circ} \mathrm{C}$ for $10 \mathrm{~min}, 95^{\circ} \mathrm{C}$ for $15 \mathrm{~s}$, and 60 ${ }^{\circ} \mathrm{C}$ for $1 \mathrm{~min}$. The last two steps were repeated 40 times. The PCR run was performed on Rotor-Gene real-time PCR system (Qiagen, Santa Clarita, CA). Allelic discrimination plots were produced in Statistical Package for The Social Sciences (SPSS version 16.0; SPSS, Chicago, IL).

In this study, we consciously used the classification launched in the original publication by Huang et al. [20]: a CRS $>0.7$ signifies patients with a high risk of advanced liver fibrosis, CRS $<0.5$ signifies a low risk of fibrosis, a CRS of 0.5 to 0.7 signifies an intermediate risk, and upon the score the patient was assigned to appropriate risk category.

\section{Statistical analysis}

Data were analyzed using SPSS 16.0. Data were presented as mean \pm standard deviation. Categorical variables were compared with the $\chi^{2}$ or Fisher's exact tests, each when appropriate, and the effect of differences was established by calculating the odds ratio with the $95 \%$ confidence interval $(95 \% \mathrm{CI})$. According to variable distribution, oneway ANOVA or nonparametric Kruskal-Wallis test was used for multi-group comparisons. The nonparametric Mann-Whitney $U$ test was used to compare median values between two groups for quantitative data. A difference between groups was significant if $P<0.05$.

\section{Results \\ Description of the study patients}

Our study started on 199 end-stage liver disease patients that were categorized into 79 Child-Pugh class A, 43 child $\mathrm{B}$, and 77 child $\mathrm{C}$. Male patients are represented $75 \%$ from child A, $81 \%$ from child B, and $75 \%$ from child $\mathrm{C}(p=0.7)$. Patients' baseline characteristics are represented in Table 2. Medical data records allowed a follow-up of only 120 patients who were eligible for liver transplantation, see Table 2.

\section{Genotyping of the seven genes}

Individual 7 candidate SNPs included in the genetic risk score (CRS) for each patient were listed in the S1 table. Some of the allelic discrimination results obtained from the real-time PCR for some genes were represented in Fig. 1

Previously, Huang et al. selected the seven genes that are involved in the cirrhosis prediction and evaluated the probability of each genotype in the cirrhotic and non-cirrhotic patients in the Caucasian population. Their findings

Table 2 Clinical data of the 199 end-stage liver disease (ChildPugh class A, child B, and child C)

\begin{tabular}{|c|c|c|c|c|}
\hline & \multicolumn{4}{|c|}{ End-stage liver disease patients } \\
\hline & Child A & Child B & Child C & $P$ value \\
\hline & $N=79$ & $N=43$ & $N=77$ & \\
\hline Age & $\begin{array}{l}60 a \\
(55-64)\end{array}$ & $\begin{array}{l}55 b \\
(51-60)\end{array}$ & $\begin{array}{l}52 c \\
(48.50-57)\end{array}$ & $<0.001 \mathrm{HS}$ \\
\hline Hb.\% & $\begin{array}{l}12.5 a \\
(11-13.70)\end{array}$ & $\begin{array}{l}12 \mathrm{~b} \\
(10.70-13)\end{array}$ & $\begin{array}{l}12 b \\
(11-13)\end{array}$ & 0.031 \\
\hline WBCsX10 3 & $\begin{array}{l}5.30 \mathrm{a} \\
(4.30-6.50)\end{array}$ & $\begin{array}{l}5.10 a \\
(4-6)\end{array}$ & $\begin{array}{l}5.60 \mathrm{a} \\
(4-6.95)\end{array}$ & 0.6 \\
\hline Platelets $\times 10^{3}$ & $\begin{array}{l}130 \mathrm{~b} \\
(96-160)\end{array}$ & $\begin{array}{l}156 \mathrm{ab} \\
(90-180)\end{array}$ & $\begin{array}{l}165 a \\
(121-210)\end{array}$ & $<0.001 \mathrm{HS}$ \\
\hline ALT & $\begin{array}{l}43 \mathrm{a} \\
(34-50)\end{array}$ & $\begin{array}{l}40 a \\
(33-47)\end{array}$ & $\begin{array}{l}46 a \\
(30-110)\end{array}$ & 0.09 \\
\hline AST & $\begin{array}{l}52 a \\
(45-63)\end{array}$ & $\begin{array}{l}48 a \\
(29-65)\end{array}$ & $\begin{array}{l}46 a \\
(21.5-86.5)\end{array}$ & 0.509 \\
\hline Alb. & $\begin{array}{l}3.50 \mathrm{~b} \\
(3.20-3.80)\end{array}$ & $\begin{array}{l}3.40 \mathrm{~b} \\
(2.80-3.80)\end{array}$ & $\begin{array}{l}3.80 \mathrm{a} \\
(3.45-4.00)\end{array}$ & $<0.001 \mathrm{HS}$ \\
\hline Creat. & $\begin{array}{l}1.00 \mathrm{a} \\
(0.90-1.10)\end{array}$ & $\begin{array}{l}1.00 \mathrm{a} \\
(0.90-1.10)\end{array}$ & $\begin{array}{l}1.00 \mathrm{a} \\
(0.90-1.10)\end{array}$ & 0.86 \\
\hline
\end{tabular}

Data are expressed as median (IQR). $H b$. states to hemoglobin, $A L T$ states to serum alanine aminotransferase, and AST states to serum aspartate aminotransferase, Alb. states to albumin

Identical letters in rows mean no significant difference at the level of 0.05 Different letters in rows mean significant difference at the level of 0.05

HS means highly significant 

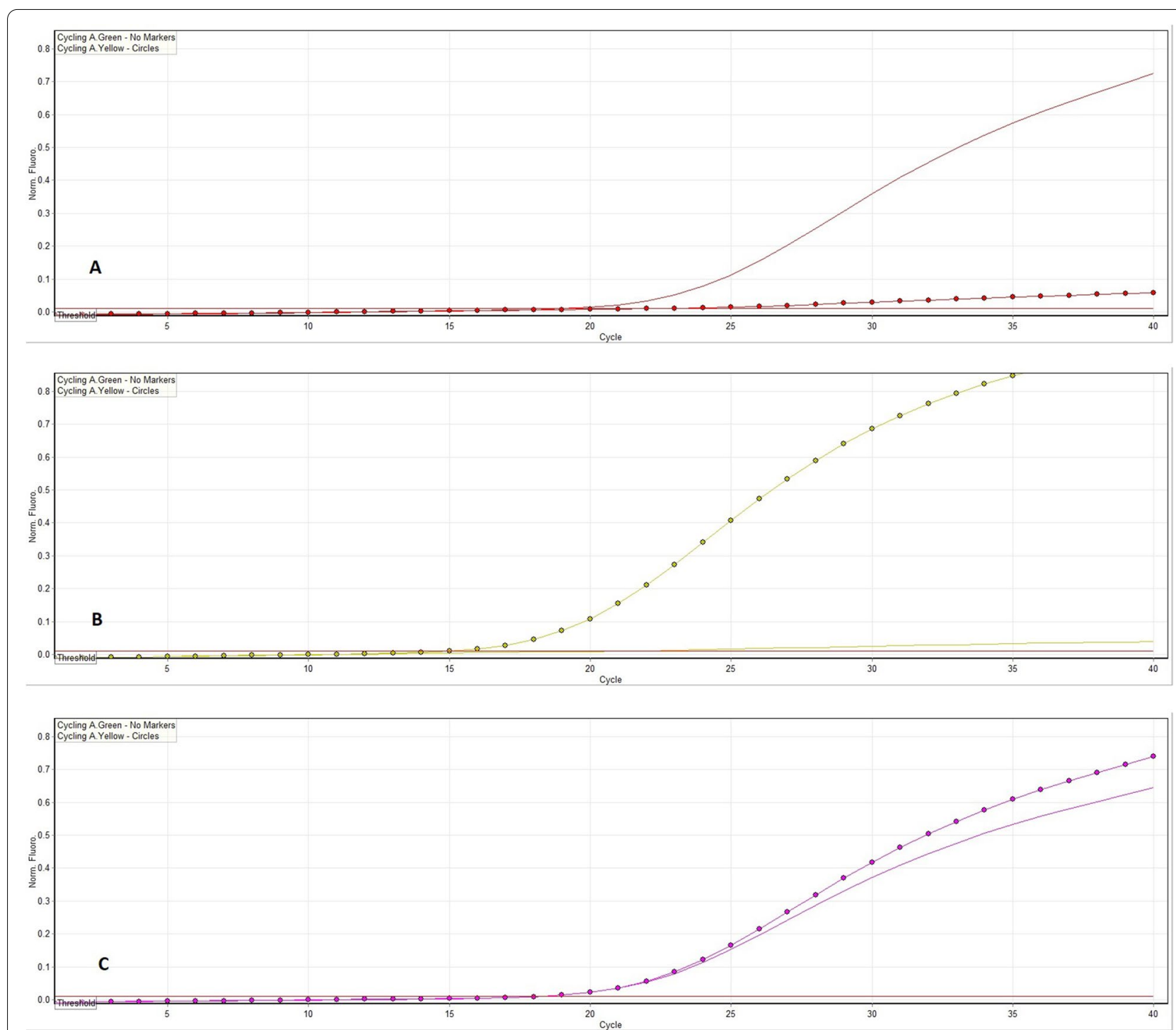

Fig. 1 Allelic discrimination curves produced by Rotor Gene real-time PCR system. The $x$-axis represents the amplification cycle number and the $y$ -axis represents the fluorescent value. (A) Example of homozygote alleles labeled with $\mathrm{FAM}^{\mathrm{TM}}$. (B) Example of homozygote alleles labeled with VIC ${ }^{\mathrm{TM}}$. (C) Example of heterozygote alleles (one labeled with $\mathrm{FAM}^{\mathrm{TM}}$ and the other labeled with $\mathrm{VIC}^{\mathrm{TM}}$ )

Table 3 CRS algorithm deduced by Huang et al. [20]

\begin{tabular}{|c|c|c|c|c|c|c|c|}
\hline Marker & Gene & SNP value $=1$ & SNP value $=0$ & $P($ snp $=1 \mid$ cirrhosis $)$ & $\begin{array}{l}P(\mathrm{snp}=1 \mathrm{l} \text { no } \\
\text { cirrhosis) }\end{array}$ & $P($ snp $=0$ l cirrhosis $)$ & $\begin{array}{l}P(\text { snp }=01 \text { no } \\
\text { cirrhosis) }\end{array}$ \\
\hline SNP 1 & AZIN1 (Chr8) & GG & GA, AA & 0.928030303 & 0.801282051 & 0.071969697 & 0.198717949 \\
\hline SNP 2 & TLR4 (Chr9) & $\mathrm{CC}$ & $\mathrm{CT}, \mathrm{TT}$ & 0.928301887 & 0.810126582 & 0.071698113 & 0.189873418 \\
\hline SNP 3 & TRPM5 (Chr11) & $\mathrm{TT}$ & $\mathrm{TC}, \mathrm{CC}$ & 0.318181818 & 0.487341772 & 0.681818182 & 0.512658228 \\
\hline SNP 4 & (AP3S2) (Chr15) & GG & $\mathrm{GA}, \mathrm{AA}$ & 0.554716981 & 0.696202532 & 0.445283019 & 0.303797468 \\
\hline SNP 5 & none (Chr1) & GG & $\mathrm{GC}, \mathrm{CC}$ & 0.78490566 & 0.610062893 & 0.21509434 & 0.389937107 \\
\hline SNP 6 & (STXBP5L)(Chr3) & GG & $\mathrm{GA}, \mathrm{AA}$ & 0.78490566 & 0.905660377 & 0.21509434 & 0.094339623 \\
\hline SNP 7 & AQP2 (Chr12) & GG & $\mathrm{GC}, \mathrm{CC}$ & 0.747169811 & 0.578616352 & 0.252830189 & 0.421383648 \\
\hline
\end{tabular}


were tabulated in Table 3 which illustrates that each SNP can take the value 0 or 1 based on the obtained genotype, and then, each value has two probabilities (assuming that the patient can be cirrhotic or non-cirrhotic). Each SNP was calculated independently of other SNPs.

The values obtained from Table 3 were substituted in the following Naïve Bayes formula:

$$
\mathrm{CRS}=\frac{0.626 * \mathrm{P}(\mathrm{S} \mid \text { cirrhosis })}{0.626 * \mathrm{P}(\mathrm{S} \mid \text { cirrhosis })+0.374 * \mathrm{P}(\mathrm{S} \mid \text { no cirrhosis })}
$$

$P(\mathrm{~S} \mid$ cirrhosis $)$ and $P(\mathrm{~S} \mid$ no cirrhosis $)$ referred to the estimated probabilities of (cirrhotic and non-cirrhotic) patients, respectively.

In the current study, we followed the same steps to build up the CRS value and to evaluate the validity of this formula in the Egyptian population.

The detailed calculation method was shown in Huang et al. [20].

\section{CRS score could expect the probability for HCC emergence}

Particularly, patients were categorized into 3 groups based on their CRS values. Patients were either at high risk (CRS7 > 0.7), intermediate risk (CRS7 0.5-0.7), or at low risk of cirrhosis (CRS7 < 0.5$)$.

The distribution of CRS value was different in child A (21.5\% low risk, $26.6 \%$ intermediate risk, and $51.9 \%$ high risk) than in child B (25.6\% low risk, $23.3 \%$ intermediate risk, and $51.2 \%$ high risk) ( $p=0.052$ ).

The median of CRS values of patients at low risk differed significantly between child A $(0.42 ; 0.39-0.44)$, child B $(0.39 ; 0.26-0.4)$, and child C $(0.39 ; 0.26-0.4)(p$ $=0.009$ ). While intermediate risk patients were differed between child A $(0.6 ; 0.59-0.6)$, child B $(0.6 ; 0.56-0.62)$, and child $C(0.6 ; 0.56-0.67)(p=0.8)$. Similarly, high-risk group median varied between child A $(0.77 ; 0.74-0.86)$, child B (0.77; 0.74-0.86), and child C $(0.77 ; 0.75-0.8)(p$ $=0.59$; see Table 4$)$.

Importantly, we also stratified the patients based on the occurrence of clinically evident HCC or not; the CRS median for patients who progressed to HCC was 0.62

Table 4 Frequency of children A, B, and C among CRS categories

\begin{tabular}{llllll}
\hline & & Child A & Child B & Child C & P value \\
\hline CRS score & Low & $0.416 \mathrm{a}$ & $0.39 \mathrm{~b}$ & $0.39 \mathrm{~b}$ & $0.009 \mathrm{~s}$ \\
& & $(0.39-0.44)$ & $(0.26-0.40)$ & $(0.26-0.40)$ & \\
& Intermedi- & $0.612 \mathrm{a}$ & $0.60 \mathrm{a}$ & $0.612 \mathrm{a}$ & $0.831 \mathrm{~ns}$ \\
ate & $(0.59-0.61)$ & $(0.56-0.62)$ & $(0.56-0.67)$ & \\
High & $0.772 \mathrm{a}$ & $0.772 \mathrm{a}$ & $0.772 \mathrm{a}$ & $0.598 \mathrm{~ns}$ \\
& $(0.74-0.86)$ & $(0.74-0.86)$ & $(0.75-0.81)$ & \\
& & &
\end{tabular}

Identical letters in rows mean no significant difference at the level of 0.05 Different letters in rows mean significant difference at the level of 0.05

$s$ means significant

ns means not significant
Table 5 Biochemical parameters of the 106 recipients post-OLT

\begin{tabular}{|c|c|c|c|c|c|}
\hline & \multicolumn{5}{|c|}{ Liver transplanted patients } \\
\hline & \multicolumn{2}{|c|}{$\mathrm{HCV}$ recurrence } & \multicolumn{2}{|c|}{ Non-recurrence } & \multirow[t]{2}{*}{$P$ value } \\
\hline & Mean & SD & Mean & SD & \\
\hline BMI & 27.41 & 2.41 & 26.83 & 2.44 & 0.339 \\
\hline Hb.\% & 11.25 & 1.18 & 11.74 & 1.13 & 0.077 \\
\hline WBCs $\times 10^{3}$ & 4.92 & 1.48 & 6.19 & 1.68 & 0.001 \\
\hline Platelets $\times 10^{3}$ & 146.00 & 38.60 & 187.52 & 33.16 & $<0.001$ \\
\hline ALT & 125.87 & 46.15 & 36.52 & 27.53 & $<0.001$ \\
\hline AST & 97.59 & 40.41 & 27.87 & 21.15 & $<0.001$ \\
\hline ALP & 141.28 & 58.55 & 73.79 & 65.87 & $<0.001$ \\
\hline GGT & 80.50 & 21.07 & 58.63 & 77.47 & $<0.001$ \\
\hline Alb. & 3.69 & 0.30 & 3.92 & 0.28 & 0.002 \\
\hline T.Bil. & 2.11 & 0.88 & 1.16 & 0.66 & $<0.001$ \\
\hline D.Bil. & 1.18 & 0.66 & .52 & 0.52 & $<0.001$ \\
\hline Urea & 42.56 & 10.61 & 41.10 & 13.46 & 0.252 \\
\hline Creat. & 1.04 & 0.32 & 1.03 & 0.25 & 0.858 \\
\hline $\mathrm{Na}$ & 139.06 & 2.03 & 138.92 & 2.57 & 0.968 \\
\hline K & 3.85 & 0.19 & 4.00 & 0.30 & 0.004 \\
\hline
\end{tabular}

Data are expressed as mean \pm standard deviation

$B M I$ body mass index, $H b$ hemoglobin, $A L T$ serum alanine aminotransferase, AST serum aspartate aminotransferase, T.Bil \& D.Bil total and direct bilirubin, respectively

(0.39-0.77) and while the CRS median for patients without HCC was $0.59(0.35-0.70)(p=0.044)$.

\section{Description of the liver transplantation patients}

From all the 106 patients, the recipient's score was available in 80 patients (CRS could not be calculated for the sake of technical complexity such as amplification failure of one the SNP reaction). Among 80 consecutive recipients, $78 \%$ were male and $22 \%$ female, with a mean age of (50.2 \pm 7.3$)$ ranging between 23 and 60 years. The mean age for the HCV recurrence group (HCV-Rec) was 50.44

Table 6 Clinical features of the 106 recipients post-OLT

\begin{tabular}{|c|c|c|c|c|c|}
\hline & \multicolumn{5}{|c|}{ Liver transplanted patients } \\
\hline & \multicolumn{2}{|c|}{$\mathrm{HCV}$ recurrence } & \multicolumn{2}{|c|}{$\begin{array}{l}\text { Non- } \\
\text { recurrence }\end{array}$} & \multirow[t]{2}{*}{$P$ value } \\
\hline & Mean & SD & Mean & SD & \\
\hline Age & 50.44 & 7.22 & 50.06 & 7.48 & 0.771 \\
\hline MELD & 17.12 & 1.88 & 17.15 & 1.86 & 0.913 \\
\hline Age of donor & 30.94 & 5.86 & 29.90 & 4.44 & 0.335 \\
\hline Donor steatosis \% & 3.81 & 2.82 & 2.23 & 2.09 & 0.009 \\
\hline HCV RNA before (IU/ml) & 564.05 & 382.79 & 571.26 & 527.23 & 0.57 \\
\hline HCV RNA post (IU/ml) & 1806.20 & 918.0 & 120.97 & 888.48 & 0.002 \\
\hline
\end{tabular}

$\mathrm{IU} / \mathrm{m} /$ international unit per $\mathrm{ml}$ 
\pm 7.2 , and it was $50.06 \pm 7.5(p=0.8)$ for the non-Rec group. The male to female ratio (M/F) was $(23 / 9)$ in the HCV Rec group and (39/9) in the non-Rec group ( $p=$ 0.3 ; see Tables 5 and 6 ).

Patients with $\mathrm{HCV}$-Rec had statistically significant higher levels of AST, ALT, GGT, ALP, total and direct bilirubin $\left(p_{\text {for all }}<0.001\right)$, and significantly lower potassium $(p=0.004)$, platelet count $(p=0.001)$, WBCs count $(p=0.001)$, and albumin level $(p=0.002)$, as compared to those in the no $\mathrm{HCV}$ recurrence (non-Rec) group. Also, urea, sodium, BMI, and creatinine levels were slightly elevated but without reaching significance. MELD score did not display any variance between the two studied groups.

To examine the role of pre and/or post-operative levels of HCV RNA on HCV-Rec frequency; each level was correlated independently with recurrence. PreOLT serum HCV RNA levels did not reveal any correlation $(p=0.8)$. On the contrary, serum HCV-RNA levels post-OLT were $1806.20 \pm 918.02 \mathrm{IU} / \mathrm{mL}$ in the HCVRec group and $1280.97 \pm 888.48 \mathrm{IU} / \mathrm{mL}$ in the non-Rec group. The mean loads of serum HCV-RNA levels after OLT were significantly related with $\operatorname{HCV} \operatorname{Rec}(p=0.002$; see Table 6).

Upon categorizing patients according to the immune suppressive regimen, 24 (77.4\%) of $\mathrm{HCV}-\mathrm{Rec}$ were treated with CNI plus MMF, 4 (13\%) were treated with CNI plus Everolimus, and $3(10 \%)$ were treated only with CNI. On the other side, 13 (27\%) of the NonRec group were treated with CNI plus MMF, 9 (19\%) were treated with CNI plus Everolimus, and 26 (54\%) were treated with CNI only. Clearly, CNI plus MMF regimen was significantly found in the HCV Rec group $(p<0.001)$.

\section{Detection of the $\mathrm{HCV}$ recurrence according to donor steatosis percentage}

To gain viewpoints on the impact of donor steatosis on $\mathrm{HCV}$ recurrences after transplantation, patients were grouped according to donor steatosis percentage into patients who have high steatosis (HS; > 3.5) and patients who have low steatosis (LS; < 3.5). Around 81\% (39) patients have non-Rec were LS, while 61\% (19) patients suffered HCV Rec were HS. On the other hand, 39\% (12) patients have HCV Rec were LS, while 19\% (9) patients have HCV Rec were HS $(p<0.001$; see Table 7$)$.

\section{Detection of the $\mathrm{HCV}$ recurrence according to CRS score}

According to the CRS score suggested by Huang et al., the patients were stratified into three risk subgroups (high risk, CRS > 0.7; moderate risk, CRS 0.5-0.7; low risk, CRS $<0.5)$. To rule whether the CRS score could discriminate between patients who experienced the $\mathrm{HCV}-\mathrm{Rec}$ group versus patients with non-Rec, the distribution of the CRS score was compared among the two groups. Among the HCV-Rec group, 27\% (8/30), $40 \%(12 / 30)$, and $33 \%(10 / 30)$ fell into the high, moderate, and low CRS risk groups, respectively. While among the non-Rec group, 30\% (13/44), 37\% (16/44), and $34 \%(15 / 44)$ fell into the high, moderate, and low CRS risk groups, respectively. Unfortunately, the association between CRS score subgroups and the HCV Rec did not reach the statistical significance $(p<0.9$; see Table 6).

Notably, the CRS values cannot predict the HCV recurrence. Even though only $33.3 \%$ of the patients (10/30) with a CRS $<0.5$ and $40 \%$ of the patients $(12 / 30)$ with a CRS of 0.5 to $0.7,27 \%$ of the patients $(8 / 30)$ with a CRS > 0.7 suffered HCV-Rec $(p=0.9)$. Importantly, the median of the CRS score was not significantly different between HCV-Rec and non-Rec patients (median $=0.6$ for both groups; $p=0.4$ ).

\section{Detection of the severity of inflammation according to CRS score}

To examine the potential role of the CRS on the hepatic inflammation, patients were gathered into mild (A0F0A1F1) and advanced inflammation (A2F2-A3F3) groups. Overall, $40 \%$ of the transplant patients progressed to at least A2F2 during follow-up, whereas $60 \%$

Table 7 Frequency of HCV recurrence among CRS categories; donor steatosis groups. CRS subgroups are high risk, CRS > 0.7; moderate risk, CRS 0.5-0.7; low risk, CRS $<0.5$

\begin{tabular}{|c|c|c|c|c|c|c|}
\hline & & \multicolumn{4}{|c|}{ Liver transplanted patients } & \multirow[t]{3}{*}{$P$ value } \\
\hline & & \multicolumn{2}{|c|}{$\mathrm{HCV}$ recurrence } & \multicolumn{2}{|c|}{ Non-recurrence } & \\
\hline & & Count & $\%$ & Count & $\%$ & \\
\hline \multirow[t]{3}{*}{ CRS SCORE } & Low risk & 10 & $33.3 \%$ & 15 & $34.1 \%$ & 0.943 \\
\hline & Moderate risk & 12 & $40.0 \%$ & 16 & $36.4 \%$ & \\
\hline & High risk & 8 & $26.7 \%$ & 13 & $29.5 \%$ & \\
\hline \multirow[t]{2}{*}{ Donor steatosis \% } & Low $<3.5$ & 12 & $38.7 \%$ & 39 & $81.3 \%$ & $<0.001$ \\
\hline & High $>3.5$ & 19 & $61.3 \%$ & 9 & $18.8 \%$ & \\
\hline
\end{tabular}


of the subjects were between A0F0 to A1F1. Around $28 \%(8 / 29)$ patients of (A2F2-A3F3) group met the high-risk CRS score, while 31\% (9/29) patients met the low-risk CRS score. On the contrary, 29\% (13/45) patients of (A0F0-A1F1) group met the high-risk CRS score, while $36 \%(16 / 45)$ patients met the low-risk CRS score $(p=0.9)$.

\section{Detection of the severity of inflammation according to donor steatosis}

To show the impact of donor steatosis on the recipient's inflammation progression, around $61 \%(19 / 29)$ of recipients have a donor with HS progressed to at least A2F2 during follow-up, whereas $19 \%(9 / 45)$ of the recipients have mild inflammation (A0F0 to A1F1). Around 81\% (39/45) of recipients have a donor with LS revealed mild inflammation (A0F0 to A1F1) and 39\% (12/29) of recipients progressed to at least A2F2 $(p<0.001)$.

\section{CRS scoring using new cutoff for $\mathrm{HCV}$ recurrence prediction}

Our latest study on $400 \mathrm{HCV}$ infected patients with different fibrosis grades concluded that our best CRS cutoff value appraised from roc curve analysis is 0.59 (under publication), accordingly the patients of the current study were regrouped into low risk with a CRS $<0.59$ and highrisk patients with a CRS above the mentioned cutoff. The patients who suffered HCV Rec represented 57\% (17/30) of high-risk CRS $>0.59$ but $41 \%(18 / 44)$ of non-Rec patients met low $\mathrm{CRS}<0.59(p=0.8)$.

\section{Stepwise logistic regression analysis}

When Stepwise logistic regression was applied to the baseline data, three features were more likely to be effective in HCV rec patients' more than non-rec: abnormal ALT [odds ratio (OR), 1.1; 95\% confidence interval (CI), 1.02-1.2] and donor steatosis $>3.5 \%$ (OR, 46.07; 95\% CI, 1.5-1407.8; see Table 7). The results of this analysis are depicted in Table 8. The CRS was not an independent predictor of HCV-Rec.

\section{Discussion}

In HCV-related hepatic cirrhosis, hepatocellular carcinoma (HCC) occurs at an annual rate of about 3\% [30]. Orthotropic liver transplantation (OLT) offers a treatment option for end-stage liver disease patients. $\mathrm{HCV}$ reinfection is nearly common after OLT, and it is estimated that up to $70 \%$ of patients will undergo histologic chronic hepatitis C [31], with a greater risk of graft rejection relative to recipients who are transplanted for other etiologies.

It is noteworthy that genetic data will be used to assess the disease risk, with possible therapeutic benefits [14, 32]. CRS score successfully differentiated chronic HCV patients with high risk versus those with low risk for cirrhosis better than clinical factors [20].

We currently examined the association of the CRS score with the probability for HCC emergence and/or the rate of $\mathrm{HCV}$ recurrence following liver transplantation. Theoretically, each of the seven most predictive markers provided only moderate predictability, whereas the combination of these 7 SNPs seems to be robust and predictive. The median of the CRS score significantly differentiates patients with clinically evident HCC from patients who did not progress to HCC. The median of the CRS score was significantly different between child $A$, child B, and child C only at a low-risk group. New researches warrant that Child-Pugh score usage as a risk prediction tool should be revisited [33]. On the other side, the median of the CRS score was not significantly different between $\mathrm{HCV}$ recurrence and non-recurrence patients. Accordingly, results in our cohort tackled that CRS cannot predict the HCV recurrence after OLT. However, a recent study shed the light on the clinical significance of the CRS genotype in the donor organ and revealed a strong association between the donor CRS and early fibrosis progression after OLT, especially in HCV-negative patients [34]. It is worth noting that the coinfection with other viruses triggers the cellular apoptosis and accelerating the HCC development. Therefore, early diagnosis of cirrhosis is crucial to avoid the mortality associated with HIV. Fernández-Rodríguez et al. reported that the diagnostic value of the CRS to deduce the liver fibrosis deterioration is limited in $\mathrm{HIV} / \mathrm{HCV}$ coinfected patients [35]. Other well-known genetic variations as IL1B and IL28B evinced a statistically significant correlation with the poor outcome post-transplantation [12].

Liver function tests were repetitively delineated to affect HCV recurrence after OLT [10, 12]. Definitely, our

Table 8 Stepwise logistic regression

\begin{tabular}{|c|c|c|c|c|c|c|c|}
\hline & & \multirow[t]{2}{*}{$B$} & \multirow[t]{2}{*}{ S.E. } & \multirow[t]{2}{*}{$P$ value } & \multirow[t]{2}{*}{ OR } & \multicolumn{2}{|c|}{ 95\% C.I. } \\
\hline & & & & & & Lower & Upper \\
\hline \multirow[t]{2}{*}{$\mathrm{HCV}$ recurrence } & ALT & 0.103 & 0.039 & 0.008 & 1.109 & 1.028 & 1.196 \\
\hline & Donor steatosis \% $(<3.5)$ & 3.830 & 1.745 & 0.028 & 46.069 & 1.508 & 1407.848 \\
\hline
\end{tabular}

S.E standard error $\mathrm{OR}$ odds ratio $\mathrm{Cl}$ confidence interval 
data showed that the increased risk of the HCV recurrence was correlated with augmented ALT, AST, and ALP levels. Feurer et al. [36] negated the correlation between liver function serum levels and disease-free survival rates. Our data shed light that HCV viral load post-transplant is significantly affecting HCV recurrence. Supportive studies affirmed that advanced donor age and/or high $\mathrm{HCV}$ viral loads post-transplant corresponded with aggressive $\mathrm{HCV}$ recurrence and allograft loss in $\mathrm{HCV}$-positive liver transplant recipients [12, 37].

Cyclosporine (as a calcineurin inhibitor (CNI))-based regimen is the main immuno-suppression protocol followed in this study. This regimen was accompanied by mycophenolate mofetil (MMF) or Everolimus. CNI is supposed to bind to the cytosolic protein cyclophilin (an immunophilin) of T-lymphocytes [38]. Mycophenolic acid acts as a selective and reversible inhibitor of Inosine5'-monophosphate dehydrogenase, whereas Everolimus is an inhibitor of mammalian target of rapamycin (mTOR) [39]. In our study, the addition of MMF to CNI positively heightens HCV recurrence rate while Everolimus did not negatively alter its rate which was supported by former studies [40].

Decisively, the outcome is better once a proper selection of patients is performed [10]. However, many surgeons have shown an augmented risk for inferior post-transplant outcomes in case of donor livers with moderate or severe large droplet macrosteatosis (ld$\mathrm{MaS}$ ), although donor livers with small droplet macrosteatosis (sd-MaS) or mild $(<30 \%)$ ld-MaS are safe for transplantation [41, 42]. The combined analysis confirmed that the degree of steatosis in donors' livers was below 3.5\% avoiding the possibility of having a worse outcome. Donor liver steatosis impacts graft function, long-term consequences of the recipient allograft, and donor hepatic recovery. Indeed, transplanting a steatotic liver may lead to reperfusion injury/ischemia that may progress to an advanced rate of early graft dysfunction. Safe cutoff for transplantation range from 10 to $30 \%$ in accordance with the transplantation center regulation $[43,44]$.

Our study is limited by the small sample size (due to sample scarcity), the absence of the donor genotype and/ or donor with macrovesicular steatosis of $30 \%$ or greater as the criterion for better comparison. No doubt that the donor genotype may synergy the genotype-phenotype association. On other point of view, the recipient genotype is more feasible and obtainable before transplantation earlier than the donor genotype. However, many studies correlated only the recipient genotype (for TLR4, IL6, and IL-28B SNPs) with the HCV recurrence [28, 41, $45,46]$, and more attention is needed to identify new predictors.

\section{Conclusions}

Based on our results, the prognostic value of the donor steatosis on HCV recurrence holds true in Egyptian $\mathrm{CHC}$ patients. Regression analysis showed that donor steatosis and ALT can significantly promote the HCV recurrence post-OLT. Because of the lack of significance, Child-Pugh score usage as a prognostic tool needs to be reassessed. Moreover, it is unlikely that CRS may be applicable in predicting the probability of $\mathrm{HCV}$ recurrence after OLT.

\section{Abbreviations \\ OLT: Orthotropic liver transplantation; CRS: Cirrhosis Risk Score; HCV: Hepatitis C virus; HCC: Hepatocellular carcinoma; MMF: Mycophenolate mofetil; CNI: Calcineurin inhibitor; TLR: Toll-like receptor; MELD: End-stage liver disease; APRI: Platelet ratio index; FIB-4: Fibrosis scoring system; ALT: Alanine ami- notranferase; AST: Aspartate aminotransferase; PLT: Platelet; RT-PCR: Real-time polymerase chain reaction; SNPs: Single-nucleotide polymorphisms; SPSS: Statistical Package for the Social Sciences; WBCs: White blood cells.}

\section{Supplementary Information}

The online version contains supplementary material available at https://doi. org/10.1186/s43141-021-00266-4.

Additional file 1: Table S1. Individual 7 candidate SNPs included in genetic risk score (CRS) and their calculated CRS score for the liver transplantation cohort.

\section{Acknowledgements}

We would like to acknowledge the STDF-Egypt/Science and Technology Development Fund (Grant No. 15002) to Reham DAWOOD for financially supporting the current research.

\section{Authors' contributions}

GS: Data curation, formal analysis, methodology, and writing- original draft. MA: Data curation, formal analysis, and methodology. TA: Formal analysis and methodology. EM: Project administration, resources, and supervision. AA: Project administration, resources, and supervision. RD: Conceptualization, methodology, funding acquisition, writing - original draft, formal analysis, investigation, supervision, and data curation. The authors have read and approved the manuscript.

\section{Funding}

The funding source (i.e., STDF; grant No. 15002 to Reham DAWOOD) has been only responsible for the financial aspects of the project and has no functional role in aspects like (study design; in the collection, analysis, and interpretation of data; in the writing of the report; and in the decision to submit the article for publication)

Availability of data and materials

All relevant data are within the paper.

\section{Declarations}

Ethics approval and consent to participate

All eligible individuals signed an informed consent form. All the steps were approved by the Ethical Review Board of the National Research Center, (NRC\# 19/072) according to Helsinki Declaration (1975). All patients encountered orthotopic LT for HCV at AI Sahel Teaching hospital, Ministry of Health and Population, Egypt, between June 2015 and October 2017

Consent for publication

Not applicable. 


\section{Competing interests}

The authors declare that they have no known competing financial interests or personal relationships that could have appeared to influence the work reported in this paper.

\section{Author details}

${ }^{1}$ Department of Microbial Biotechnology, Genetic Engineering Division, National Research Centre, Dokki, P.O. 12622, Giza, Egypt. ²Department of Endemic Medicine and Hepato-gastroenterology, Faculty of Medicine, Cairo University, Cairo, Egypt.

Received: 6 June 2021 Accepted: 5 October 2021

Published online: 10 November 2021

\section{References}

1. Ravi S, Axley P, Jones DA, Kodali S, Simpson H, McGuire BM et al (2017) Unusually high rates of hepatocellular carcinoma after treatment with direct-acting antiviral therapy for hepatitis $C$ related cirrhosis. Gastroenterology 152:911-912. https://doi.org/10.1053/j.gastro.2016.12.021

2. Roche B, Coilly A, Jean Duclos-Vallee C, Samuel D (2018) The impact of treatment of hepatitis $C$ with DAAs on the occurrence of HCC. Liver Int 38:139-145. https://doi.org/10.1111/liv.13659

3. Kassas ME, Funk AL, Salaheldin M, Shimakawa Y, Eltabbakh M, Jean K et al (2018) Increased recurrence rates of hepatocellular carcinoma after DAA therapy in a hepatitis C-infected Egyptian cohort: a comparative analysis. JViral Hepat 25. https://doi.org/10.1111/jvh.12854

4. Popping S, Bade D, Boucher C, van der Valk M, El-Sayed M, Sigurour O et al (2019) The global campaign to eliminate HBV and HCV infection: international viral hepatitis elimination meeting and core indicators for development towards the 2030 elimination goals. J Virus Erad 5:60-66

5. Duseja A (2014) Staging of hepatocellular carcinoma. J Clin Exp Hepatol 4:S74-S79. https://doi.org/10.1016/j.jceh.2014.03.045

6. Krige J, Spence RT, Jonas E, Hoogerboord M, Ellsmere J (2020) A new recalibrated four-category Child-Pugh Score performs better than the original Child-Pugh and MELD scores in predicting in-hospital mortality in decompensated alcoholic cirrhotic patients with acute variceal bleeding: a real-world cohort analysis. World J Surg 44:241-246. https://doi. org/10.1007/s00268-019-05211-8

7. Abdelaziz AO, Nabil MM, Omran DA, Abdelmaksoud AH, Asem N, Shousha Hl et al (2020) Hepatocellular carcinoma multidisciplinary Clinic-Cairo University (HMC-CU) score: a new simple score for diagnosis of HCC. Arab J Gastroenterol 21:102-105. https://doi.org/10.1016/j.ajg.2020.04.001

8. Hamdorf M, Kawakita S, Everly M (2017) The potential of microRNAs as novel biomarkers for transplant rejection. J Immunol Res 2017:4072364. https://doi.org/10.1155/2017/4072364

9. Han Z-B, Zhong L, Teng M-J, Fan J-W, Tang H-M, Wu J-Y et al (2012) Identification of recurrence-related microRNAs in hepatocellular carcinoma following liver transplantation. Mol Oncol 6:445-457. https://doi.org/10. 1016/j.molonc.2012.04.001

10. Vinaixa C, Rubín A, Aguilera V, Berenguer M (2013) Recurrence of hepatitis C after liver transplantation. Ann Gastroenterol 26:304-313

11. Sotiropoulos GC, Tagkalos E, Fouzas I, Vernadakis S, Mathé Z, Treckmann J et al (2012) Liver transplantation for hepatocellular carcinoma using extended criteria donor grafts. Transplant. Proc. https://doi.org/10.1016/j. transproceed.2012.09.021

12. El Awady MK, Bader El Din NG, Abdel Aziz Riad M, Omran MH, Abdelhafez TH, Elbaz TM et al (2014) Predictors of disease recurrence post living donor liver transplantation in end stage chronic HCV patients. Dis Markers 2014. https://doi.org/10.1155/2014/202548

13. Kelava T, Turcic P, Markotic A, Ostojic A, Sisl D, Mrzljak A (2020) Importance of genetic polymorphisms in liver transplantation outcomes. World J Gastroenterol 26:1273-1285. https://doi.org/10.3748/WJG.V26.112.1273

14. Shi G, Wang C, Zhang P, Ji L, Xu S, Tan X et al (2017) Donor polymorphisms of Toll-like receptor 4 rs 1927914 associated with the risk of hepatocellular carcinoma recurrence following liver transplantation. Arch Med Res 48:553-560. https://doi.org/10.1016/j.arcmed.2017.11.011

15. de la Fuente S, Citores M-J, Lucena J-L, Muñoz P, Cuervas-Mons V (2019) TLR9-1486C/T polymorphism is associated with hepatocellular carcinoma recurrence after liver transplantation. Biomark Med 13:9951004. https://doi.org/10.2217/bmm-2019-0030

16. Zhang T, Liu Y, Peng X, Fan J, Peng Z (2017) Association between recipient IL-15 genetic variant and the prognosis of HBV-related hepatocellular carcinoma after liver transplantation. Dis Markers 2017. https://doi.org/10. $1155 / 2017 / 1754696$

17. Imai H, Kamei H, Onishi Y, Ishizu Y, Ishigami M, Goto H et al (2018) Diagnostic usefulness of APRI and FIB-4 for the prediction of liver fibrosis after liver transplantation in patients infected with hepatitis $C$ virus. Transplant Proc 50:1431-1436. https://doi.org/10.1016/j.transproceed.2018.03.005

18. Kartoun U (2019) Toward an accelerated adoption of data-driven findings in medicine: research, skepticism, and the need to speed up public visibility of data-driven findings. Med Heal Care Philos 22:153-157. https:// doi.org/10.1007/s11019-018-9845-y

19. Thomas DL, Thio CL, Martin MP, Qi Y, Ge D, Ohuigin C et al (2009) Genetic variation in IL28B and spontaneous clearance of hepatitis C virus. Nature. https://doi.org/10.1038/nature08463

20. Huang H, Shiffman ML, Friedman S, Venkatesh R, Bzowej N, Abar OT et al (2007) ORIGINAL ARTICLES A 7 gene signature identifies the risk of developing cirrhosis in patients with chronic hepatitis C. Hepatology 46:297-306. https://doi.org/10.1002/hep.21695

21. Carulli $L$ (2015) Telomere shortening as genetic risk factor of liver cirrhosis. World J Gastroenterol 21:379-383. https://doi.org/10.3748/wjg.v21.i2.379

22. Okugawa Y, Toiyama Y, Shigeyasu K, Yamamoto A, Shigemori T, Yin C, ... Goel A (2018) Enhanced AZIN1 RNA editing and overexpression of its regulatory enzyme ADAR1 are important prognostic biomarkers in gastric cancer. J Transl Med 16(1). https://doi.org/10.1186/s12967-018-1740-z

23. Salum GM, Dawood RM, Abd el-Meguid M, Ibrahim NE, Abdel Aziz AO, El Awady MK (2019) Correlation between IL28B/TLR4 genetic variants and HCC development with/without DAAs treatment in chronic HCV patients. Genes Dis. https://doi.org/10.1016/j.gendis.2019.05.004

24. Peng L, Guo J, Zhang Z, Liu L, Cao Y, Shi H, ... Wang J (2017) Polymorphisms of AZIN1 rs2679757 and TRPM5 rs886277 are Associated with Cirrhosis Risk in Chinese Patients with Chronic Hepatitis B. Infect Int 1(2):103-109. https://doi.org/10.1515/ii-2017-0016

25. Kraveka JM, Li L, Szulc ZM, Bielawski J, Ogretmen B, Hannun YA, ... Bielawska A (2007) Involvement of dihydroceramide desaturase in cell cycle progression in human neuroblastoma cells. J Biol Chem. https://doi.org/ 10.1074/jbc.M700647200

26. Zhu Q, Yamakuchi M, Ture S, De La Luz Garcia-Hernandez M, Ko KA Modjeski KL, ... Lowenstein CJ (2014) Syntaxin-binding protein STXBP5 inhibits endothelial exocytosis and promotes platelet secretion. J Clin Invest 124(10):4503-4516. https://doi.org/10.1172/JCI71245

27. Takata K (2006) Aquaporin-2 (AQP2): Its intracellular compartment and trafficking. Cell Mol Biol. https://doi.org/10.1170/T747

28. Dawood RM, Salum GM, Abd El-Meguid M, Shemis M, Abdel Aziz AO, El Awady MK (2020) Recipient interleukin 6 gene polymorphism and expression predict HCV recurrence post liver transplantation. Gene 754:144887. https://doi.org/10.1016/j.gene.2020.144887

29. Dawood RM, Salum GM, El-Meguid MA, Elsayed A, Yosry A, Abdelaziz A et al (2021) Development of a gene signature for predicting cirrhosis risk score of chronic liver disease associated with HCV infection in Egyptians. Microb Pathog 104805. https://doi.org/10.1016/j.micpath.2021.104805

30. Abd Alla MDA, Dawood RM, Rashed HAEH, Farrag G, Ammar IAE, Mahmoud MMAH et al (2021) Treatment of hepatitis C virus infection with direct-acting antivirals plus ribavirin eliminates viral RNA from peripheral blood mononuclear cells and reduces virologic relapse in diverse hepatic parenchymal changes. Arch Virol 166:1071-1081. https:// doi.org/10.1007/s00705-021-04969-4

31. Gallegos-Orozco JF, Yosephy A, Noble B, Aqel BA, Byrne TJ, Carey EJ et al (2009) Natural history of post-liver transplantation hepatitis C: a review of factors that may influence its course. Liver Transplant 15:1872-1881. https://doi.org/10.1002/lt.21954

32. Dawood RM, El-Meguid MA, Salum GM, El Awady MK (2020) Key players of hepatic fibrosis. J Interf Cytokine Res:jir.2020.0059. https://doi.org/10. 1089/jir.2020.0059

33. Kok B, Abraldes JG (2019) Child-Pugh classification: time to abandon? Semin Liver Dis 39:96-103. https://doi.org/10.1055/s-0038-1676805

34. Zimmermann A, Darstein F, Hoppe-Lotichius M, Toenges G, Lautem A, Abel F et al (2019) Cirrhosis risk score of the donor organ predicts early 
fibrosis progression after liver transplantation. J Gastrointestin Liver Dis 28:53-61. https://doi.org/10.15403/jgld.2014.1121.281.crr

35. Fernández-Rodríguez A, Berenguer J, Jiménez-Sousa MA, GuzmánFulgencio M, Micheloud D, Miralles P et al (2013) Prediction of hepatic fibrosis in patients coinfected with HIV and hepatitis $C$ virus based on genetic markers. J Acquir Immune Defic Syndr 64:434-442. https://doi. org/10.1097/QAl.0b013e3182a06eb6

36. Feurer ID, Wright JK, Payne JL, Kain AC, Wise PE, Hale P et al (2002) Effects of hepatitis $C$ virus infection and its recurrence after liver transplantation on functional performance and health-related quality of life. J Gastrointest Surg. https://doi.org/10.1016/S1091-255X(01)00002-6

37. Khettry U, Huang WY, Simpson MA, Pomfret EA, Pomposelli JJ, Lewis WD et al (2007) Patterns of recurrent hepatitis $C$ after liver transplantation in a recent cohort of patients. Hum Pathol. https://doi.org/10.1016/j.humpa th. 2006.08.028

38. Jeng L-B, Gyu Lee S, Singh Soin A, Lee W-C, Suh K-S, Jin Joo D et al (2018) Efficacy and safety of everolimus with reduced tacrolimus in living-donor liver transplant recipients: 12-month results of a randomized multicenter study. Am J Transpl 18:1435-1446. https://doi.org/10.1111/ajt.14623

39. Ventura-Aguiar P, Campistol JM, Diekmann F (2016) Safety of mTOR inhibitors in adult solid organ transplantation. Expert Opin Drug Saf. https://doi.org/10.1517/14740338.2016.1132698

40. Nelson DR, Soldevila-Pico C, Reed A, Abdelmalek MF, Hemming AW, Van Der Werf WJ et al (2001) Anti-interleukin-2 receptor therapy in combination with mycophenolate mofetil is associated with more severe hepatitis C recurrence after liver transplantation. Liver Transplant. https://doi.org/ $10.1053 /$ /lts.2001.29414
41. Dhillon N, Walsh L, Krüger B, Ward SC, Godbold JH, Radwan M et al (2010) A single nucleotide polymorphism of Toll-like receptor 4 identifies the risk of developing graft failure after liver transplantation. J Hepatol. https:// doi.org/10.1016/j.jhep.2009.12.044

42. Jackson KR, Long J, Philosophe B, Garonzik-Wang J (2019) Liver transplantation using steatotic grafts. Clin Liver Dis 14:191-195. https://doi.org/10. $1002 / c l d .847$

43. Salama IAK, Dessouky BAM, Korayem EM, Aal SA (2010) Impact of multislice spiral computed tomography on donor selection and surgical planning in living-related liver transplant. Exp Clin Transplant

44. Vernuccio F, Whitney SA, Ravindra K, Marin D (n.d.) CT and MR imaging evaluation of living liver donors. Abdom Radiol 1:3. https://doi.org/10. 1007/s00261-019-02385-6

45. Charlton MR, Thompson A, Veldt BJ, Watt K, Tillmann H, Poterucha JJ et al (2011) Interleukin-28B polymorphisms are associated with histological recurrence and treatment response following liver transplantation in patients with hepatitis C virus infection. Hepatology. https://doi.org/10. 1002/hep.24074

46. Agúndez JA, García-Martín E, Devesa MJ, Carballo M, Martínez C, LeeBrunner A et al (2012) Polymorphism of the TLR4 gene reduces the risk of hepatitis C virus-induced hepatocellular carcinoma. Oncology 82:35-40. https://doi.org/10.1159/000335606

\section{Publisher's Note}

Springer Nature remains neutral with regard to jurisdictional claims in published maps and institutional affiliations.

\section{Submit your manuscript to a SpringerOpen ${ }^{\circ}$ journal and benefit from:}

- Convenient online submission

- Rigorous peer review

- Open access: articles freely available online

- High visibility within the field

- Retaining the copyright to your article

Submit your next manuscript at $\boldsymbol{\nabla}$ springeropen.com 